\title{
Health supplement consumption behavior in the older adult population: an exploratory study
}

\author{
Mimi Tse ${ }^{1}{ }^{*}$, Ka Long Chan ${ }^{1}$, Anthony Wong ${ }^{1}$, Eric Tam ${ }^{2}$, Elaine Fan ${ }^{3}$ and Gloria Yip ${ }^{3}$ \\ ${ }^{1}$ Center for Gerontological Nursing, School of Nursing, The Hong Kong Polytechnic University, Hong Kong, China \\ ${ }^{2}$ Interdisciplinary Division of Biomedical Engineering, The Hong Kong Polytechnic University, Hong Kong, China \\ ${ }^{3}$ Senior Citizen Home Safety Association, Hong Kong, China
}

\section{Edited by:}

Gerry Leisman, The National Institute for Brain and Rehabilitation Sciences, Israel

\section{Reviewed by:}

Xiaolin Zhou, Peking University, China Angela Sy, University of Hawaii at Manoa, USA

*Correspondence:

Mimi Tse, Center of Gerontological Nursing, School of Nursing, The Hong Kong Polytechnic University, Hung Hom, Kowloon, Hong Kong e-mail:mimi.tse@polyu.edu.hk
Health supplement consumption behavior is important to maintain health status. The purpose of the study was to explore the spending pattern on health supplement consumption behavior in Hong Kong older adults population. The present study was a cross-sectional survey study; and was collected from via a street-intercept interview. Participants were approached and invited to response to a questionnaire. The location for data collection was evenly distributed in Hong Kong, Kowloon, and New Territories. The questionnaire included demographic data and source of income source, spending habits on health supplement products, and whether they performed regular health check. There were 982 participants interviewed; and $46 \%$ was male and $54 \%$ was female. The participants are divided into young-old (age 50-69) and old-old group (age 70 or above). The mean age is $67.93 \pm 10.386$. Most of the participants have regular body check; the major reason is to maintain health. Less than half of the participants spent money on health supplement products; the major reason for such purchase was to maintain health; while for not buying is, they did not think that would have any effect in their health. Also, more young-old participants have regular body check and spend more money on health supplement products; while old-old group participants were less likely to concern their health, and they were less likely to perform regular body check and purchase health supplement products. The present research reveals the pattern of the health supplement consumption behavior of young-old and oldold. Young-old group and old-old group have difference pattern according to their difference age-related health condition and the amount of spare money. Different educational program concern health consciousness and promotion strategy of regular body check and health supplement products need be tailor-made for older adults, and for young-old and old-old groups.

Keywords: health-related consumption behavior, aging, older adult, health promotion, Hong Kong population

\section{INTRODUCTION}

According to the World Health Organization (WHO), the aging population is increasing faster than any other (1). The population aged 65 and over is expected to increase by $180 \%$ between 2010 and 2050 as compared to an anticipated $32 \%$ increase in the population aged between 15 and 64 (2). Hong Kong is no exception to this global trend. According to the Census and Statistics Department, HKSAR, the proportion of the population aged 65 and over will increase from 13\% in 2011 to $30 \%$ in 2041. By contrast, the population aged 15-64 will decrease from 75 to $61 \%$ in the same period (3). There is a negative relationship between health and age (4), thus, older adults have worse health status than younger adults. A report in 2013 reveals that the population aged 65 and over in Hong Kong has the poorest health status of all age groups, based on a self-perceived general health condition questionnaire (4). They also have the highest proportion of individuals suffering from chronic health conditions, at $73 \%$ (4). The four most common chronic diseases are hypertension (62\%), diabetes mellitus (27\%), high cholesterol (18\%), and heart disease (13\%) (4). Growing older can therefore be said to contribute to declining health.
The WHO Ottawa Charter for Health Promotion introduced the concept of health promotion, defined as "the process of enabling people to increase control over, and to improve, their health." Health is seen as a resource for everyday life beyond the responsibility of the health section as a way to achieve well-being. Good health is a major resource for social, economic, and personal development and an important dimension of quality of life. Professional and social groups and health personnel have a major responsibility to mediate between differing interests in society for the pursuit of health. Health promotion focuses on achieving equity in health (5). Specific health promotion behaviors and practices would include living a healthy lifestyle, receiving regular physical checkups, and using health supplement products.

Health supplement consumer behavior refers to buying health supplement products and receiving physical checkups. Several studies have examined health supplement consumer behavior, but they did not focus on older adults. Research shows that those with higher health consciousness are more willing to use functional foods (6), that the high nutritional value of food is the most important factor in determining their health food purchases (7), 
that perceived behavioral control and attitude toward healthy eating are the most important predictors of healthy eating behavior in adolescents (8), and that advertisements from medical professionals are useful to consumers in buying health supplement products (9). However, there is a lack of research on older adults' health supplement consumer behavior.

Health supplement consumer behavior is important to older adults; they can maintain and enhance their health status through purchasing health food, and get regular physical checkups to monitor their health condition. However, aging has an effect on cognition, thus older and younger adults have different cognitive ability (10). Older adults have impaired processing speed, working memory, and long-term memory, thus they have different ways of processing the information they receive. Only self-perceived important information and that requiring fewer cognitive resources can get processed in older adults. Thus, older adults and younger adults behave differently when it comes to decision making, particularly as regards consumer behavior.

Because older adults have a different decision-making processes, there is a knowledge gap in terms of health supplement consumer behavior as it applies to older adults. Thus, there is a need to examine the underlying process of older adults' decision making in this area. Based on evidence from the empirical study, messages and advertisements about health supplement products can be framed for older adults, and strategies on health supplement product marketing can be tailored to older adults. Therefore, the aim of this research was to explore the Hong Kong older adult population's spending patterns on health supplement products and their usage of regular physical checkups.

\section{MATERIALS AND METHODS DATA COLLECTION}

This was a cross-sectional survey study, with older adults' consumer behavior data collected from a street-intercept questionnaire. The target was those aged 50 or over; participants were divided into a young-old and an old-old group according to their age, either 50-69 or 70 and over, respectively. The Hong Kong government offered an old age allowance for Hong Kong residents aged 70 and above, therefore we set the cut-off age as 70 . The interview locations were in private housing complexes in Hong Kong, Kowloon, and the New Territories. The sample size was based on data from the Census and Statistics Department in 2011 (11); the total population of Hong Kong was 7,070,338, of whom 35.4\% $(n=2,501,105)$ were aged 50 or above. By setting $\alpha=0.01$ and with a $5 \%$ of margin of error, the estimated sample size was 609 . Using proportional sampling, the sample sizes for Hong Kong, Kowloon, and the New Territories were 118, 193, and 298, respectively. The target population was approached individually, and they were invited to join our study by answering the questionnaire administered by the research team. The estimated time needed to complete the questionnaire was around $10 \mathrm{~min}$.

\section{MEASURES}

The questionnaire comprised three parts, of which the first elicited the subject's demographic data, including age, gender, marriage status, education level, income source, and living status. The second covered expenditure, and consisted of two questions:
"After deducting basic expenses, what is your monthly disposable income?" and "Do you have enough money to pay for your daily necessities?" The third part covered health supplement consumer behavior and its definition included having regular physical checkups and purchasing health supplement products. Examples of health supplement products included health supplement food (cod liver oil, ganoderma spores, calcium tablets), medical equipment (blood pressure and blood glucose measurement devices), and drugs. It contained three questions, "Do you have regular physical checkups?" "Do you purchase health supplement products?" and "Do you introduce health supplement products to others?". Respondents were asked to give their reasons after answering each question. Questions were closed-ended with multiple choice answers from which respondents were asked to choose the most suitable answers.

\section{DATA ANALYSIS}

The statistical software SPSS (Version 20) was used to process and analyze the quantitative data. Intention-to-treat analysis was conducted for any missing data. Descriptive statistics were generated to illustrate the characteristics of the young-old and old-old group participants. The Chi-squared test was used to compare the group differences. A $p$-value of $<0.05$ was considered statistically significant for all statistical testing.

\section{RESULTS \\ DEMOGRAPHIC DATA}

As shown in Table 1, nine hundred eighty-two older people, $46 \%$ male and $54 \%$ female, participated in this interview. The participants were divided into a young-old and an old-old group. The mean age was $67.93 \pm 10.386$. The sampling locations were in private housing estates in Hong Kong, Kowloon, and the New Territories (19, 32, and 49\%, respectively). Most of the participants were married $(81 \%$ for the young-old and $68 \%$ for the old-old group). In terms of education, $72 \%$ of the young-old participants had reached secondary level, while only $42 \%$ of the old-old participants had reached secondary level.

In terms of income sources, most of the young-old participants relied on the salary from their job, support from their children, and their savings $(45,39$, and $23 \%$, respectively), while the oldold participants relied on support from their children, OAA, and their personal savings $(67,65$, and $24 \%$, respectively).

Regarding living status, most of the participants lived in privately owned housing ( $60 \%$ for the young-old group and $44 \%$ for the old-old group), while $18 \%$ lived with family members, $12 \%$ lived in public rental housing, and $7 \%$ lived in private rental housing, respectively, among the young-old group, which was similar to the old-old group $(34,15$, and $4 \%$, respectively). Overall, there were statistically significant differences between the two groups in terms of marriage status, education level, income source, and living status.

\section{EXPENDITURE}

In terms of disposable income, $21 \%$ of participants in the youngold group had $<\$ 1500$ per month, 27\% had $\$ 1500-\$ 2999,19 \%$ had $\$ 3000-\$ 4999$, and 30\% had more than $\$ 4500$ after deducting 


\begin{tabular}{|c|c|c|c|c|}
\hline & $\begin{array}{c}\text { Total }(N=982) \\
N(\%)\end{array}$ & $\begin{array}{c}50-69(N=493) \\
N(\%)\end{array}$ & $\begin{array}{c}70 \text { and over }(N=488) \\
N(\%)\end{array}$ & $p$-Value \\
\hline Age & \multicolumn{4}{|c|}{$67.93(10.386)$} \\
\hline Male & $445(45.6)$ & $228(46.6)$ & $217(44.6)$ & 0.517 \\
\hline Female & $531(54.4)$ & $261(53.4)$ & $270(55.4)$ & \\
\hline Divorce & 119 (12.3) & $47(9.8)$ & $72(14.9)$ & \\
\hline Single & $40(4.1)$ & $29(6.0)$ & $11(2.3)$ & \\
\hline Widowed & $84(8.7)$ & $15(3.1)$ & $69(14.3)$ & \\
\hline \multicolumn{5}{|l|}{ Interview location } \\
\hline Hong Kong & $186(19.0)$ & $94(19.1)$ & 92 (18.9) & 0.446 \\
\hline Primary level & $275(28.2)$ & $127(25.8)$ & $148(30.6)$ & \\
\hline Secondary level & $404(41.4)$ & $248(50.4)$ & $156(32.2)$ & \\
\hline Tertiary level or above & $156(16.0)$ & $108(22.0)$ & $48(9.9)$ & \\
\hline \multicolumn{5}{|l|}{ Income source ${ }^{a}$} \\
\hline Supported by children & $524(53.4)$ & $194(39.4)$ & $330(67.6)$ & $0.000 * *$ \\
\hline OAA & $338(34.5)$ & $20(4.1)$ & $318(65.2)$ & \\
\hline Working & $235(24.0)$ & $223(45.2)$ & $12(2.5)$ & \\
\hline Savings & $236(24.1)$ & $116(23.5)$ & $120(24.6)$ & \\
\hline Pension & $122(12.4)$ & $65(13.2)$ & $57(11.7)$ & \\
\hline Investment & $88(9.0)$ & $59(12.0)$ & $29(5.9)$ & \\
\hline Other & $6(0.6)$ & $2(0.4)$ & $4(0.8)$ & \\
\hline
\end{tabular}

Chi-square was used.

${ }^{*} p<0.01$ was considered to be statistically significant.

${ }^{a}$ Multiple responses.

their necessary living expenses. In the old-old group, 39\% of participants had $<\$ 1500$ of disposable income, 30\% had $\$ 1500$ $\$ 2999,11 \%$ had $\$ 3000-\$ 4999$, and only $16 \%$ had more than $\$ 4500$ per month. The percentage of disposable income was statistically significantly different between the two age groups, $X^{2}(4$, $N=982)=60.31, p<0.01$ (see Table 2).

Regarding the adequacy of money for their daily necessities, $8 \%$ of the young-old group did not have enough money, $36 \%$ had barely enough, $39 \%$ had enough, and $15 \%$ had more than enough money. In the old-old group, $7 \%$ of participants did not have enough money, $44 \%$ had barely enough, 38\% had enough, and 9\% had more than enough money. The young-old and old-old had a statistically significant difference in the adequacy of money, $X^{2}(3, N=982)=11.26, p=0.01$ (see Table 2$)$.

\section{HEALTH SUPPLEMENT CONSUMPTION BEHAVIOR}

In terms of physical checkups, most of the participants had them regularly (73\% for the young-old and $80 \%$ for the old-old group). The frequency of their checkups were statistically significantly different between the two age groups, $X^{2}(1, N=982)=8.26$, $p<0.01$. The major reason for having regular checkups was to maintain health $(73 \%$ for the young-old and $64 \%$ for the oldold group), and because it was requested by others (10\% for the young-old and $20 \%$ for the old-old), while the major reasons for not having regular physical checkups were that they were not needed (74\% for the young-old and $61 \%$ for the oldold), and cost too much (14\% for the young-old and $23 \%$ for the old-old). Overall, young-old and old-old were statistically significantly different in their reasons both for having regular 


\begin{tabular}{|c|c|c|c|c|}
\hline & $\begin{array}{c}\text { Total }(N=982) \\
N(\%)\end{array}$ & $\begin{array}{c}50-69(N=493) \\
N(\%)\end{array}$ & $\begin{array}{c}70 \text { and over }(N=488) \\
N(\%)\end{array}$ & $p$-Value \\
\hline \multicolumn{5}{|c|}{ After deducting basic living expenses, how much money is left for you to spend each month? } \\
\hline$\$ 1500-\$ 2999$ & $284(29.0)$ & $136(27.6)$ & $148(30.5)$ & \\
\hline$\$ 3000-\$ 4499$ & $154(15.7)$ & $96(19.5)$ & 58 (11.9) & \\
\hline \multicolumn{5}{|c|}{ Do you have enough money to supply the necessities of life? } \\
\hline Not enough, and living is difficult & $78(8.0)$ & $40(8.2)$ & $38(7.9)$ & $0.010^{*}$ \\
\hline Barely enough & $395(40.6)$ & $179(36.6)$ & $216(44.6)$ & \\
\hline Enough, have money left over & $380(39.1)$ & 195 (39.9) & $185(38.2)$ & \\
\hline More than enough & $120(12.3)$ & 75 (15.3) & $45(9.3)$ & \\
\hline
\end{tabular}

Chi-square was used.

${ }^{*} p<0.05$ and ${ }^{*} p<0.01$ were considered to be statistically significant.

Table 3 | Health supplement consumption behavior.

\begin{tabular}{|c|c|c|c|c|}
\hline & $\begin{array}{c}\text { Total }(N=982) \\
N(\%)\end{array}$ & $\begin{array}{c}50-69(N=493) \\
N(\%)\end{array}$ & $\begin{array}{c}70 \text { and over }(N=488) \\
N(\%)\end{array}$ & $p$-Value \\
\hline \multicolumn{5}{|c|}{ Do you have regular physical exams? ${ }^{a}$} \\
\hline Health & $517(69.2)$ & 266 (73.9) & $251(64.9)$ & \\
\hline Requested by others & $114(15.3)$ & $36(10.0)$ & $78(20.2)$ & \\
\hline Convenience & $6(0.8)$ & $4(1.1)$ & $2(0.5)$ & \\
\hline No, reason(s): & $225(22.9)$ & $132(26.8)$ & $93(19.1)$ & \\
\hline No need & $150(69.1)$ & $95(74.2)$ & $55(61.8)$ & \\
\hline High cost & $39(18.0)$ & $18(14.1)$ & $21(23.6)$ & \\
\hline No time & $29(13.4)$ & $16(12.5)$ & $13(14.6)$ & \\
\hline Health supplement food & $232(62.9)$ & $150(69.4)$ & $82(53.6)$ & \\
\hline Medical equipment & $159(43.1)$ & $86(39.8)$ & $73(47.7)$ & \\
\hline Drugs & $10(2.7)$ & $1(0.5)$ & $9(5.9)$ & \\
\hline No & $609(62.1)$ & $275(55.8)$ & $334(68.4)$ & \\
\hline \multicolumn{5}{|c|}{ Do you introduce health supplement products to others? } \\
\hline Yes & $151(41.5)$ & $111(52.4)$ & $40(26.3)$ & $0.000 * *$ \\
\hline No & $213(58.5)$ & $101(47.6)$ & $112(73.7)$ & \\
\hline
\end{tabular}

Chi-square was used.

${ }^{*} p<0.01$ was considered to be statistically significant.

${ }^{a}$ Multiple responses.

checkups, $X^{2}(5, N=982)=23.27, p<0.01$ and for not having regular checkups, $X^{2}(5, N=982)=7.54, p=0.18$ (see Table 3 ).

Regarding the purchase of health supplement products, fewer than half of the participants spent money on these ( $44 \%$ for the young-old and $31 \%$ for the old-old group). The percentage of purchasing health supplement products among participants was statistically significantly different between the two age groups, $X^{2}(1, N=982)=16.70, p<0.01$. Expenditure on health supplement products made up $69 \%$ of health expenditure for the young-old and 53\% for the old-old group, and that on medical equipment represented $39 \%$ of health spending for the youngold and $47 \%$ for the old-old group. These frequencies were 
statistically significantly different across the two age groups, $X^{2}(3$, $N=982)=21.89, p<0.01$ (see Table 3).

As regards introducing health supplement products to others, $52 \%$ of young-old participants had done so, compared with only $23 \%$ of old-old participants. The relationship between introducing health supplement products to others and age group was statistically significant, $X^{2}(1, N=982)=24.73, p<0.01$. The oldold were less likely to introduce health supplement products to others (see Table 3).

\section{REASONS FOR PURCHASING HEALTH SUPPLEMENT PRODUCTS}

In terms of their reasons for buying health supplement products, most of the participants did so for health maintenance ( $68 \%$ for the young-old and $63 \%$ for the old-old group), while the less major reasons were introduction by family members or friends $(20 \%$ for the young-old and $24 \%$ for the old-old group) and introduction by medical professionals ( $16 \%$ for the young-old and $26 \%$ for the old-old). These frequencies were statistically significantly different between the two age groups, $X^{2}(7, N=982)=14.90, p=0.04$ (see Table 4).

Regarding their reasons for not buying health supplement products, in the majority of cases, it was because they believed that the products had no effect (51\% for the young-old and $41 \%$ for the old-old), while the less major reasons were high cost $(21 \%$ for the young-old and $25 \%$ for the old-old), and uncertainty regarding the effect of the products (13\% for the young-old and $18 \%$ for the old-old). These frequencies were not statistically significantly different between the two age groups, $X^{2}(7, N=982)=14.46$, $p=0.11$ (see Table 4).

\section{DISCUSSION}

The present study investigated the health supplement consumer behavior of people aged 50 and above, mainly in terms of receiving regular physical checkups and purchasing health-related products. The findings show that the amount of disposable income may be not related to the adequacy of income. Table 2 shows the difference between the two groups in the amount of available spending money, with the young-old group nearly equally distributed across the four spending money brackets, while the majority of the oldold group had $<\$ 3000$ available per month after meeting living expenses. This suggests that the old-old group has less spending money available than the young-old group. However, there were similar patterns in the sufficiency of money among the two groups: both were concentrated in the "barely enough" and "enough" categories. Although the amount of available spending money differed, this did not influence their perception of its adequacy. One possible reason is that old-old participants reduce their expenses in order to manage the necessities of daily life. They do this by lowering their quality of life, avoiding unnecessary expenses, and reducing the number of entertainment activities. Another reason is that they rely on other subsidies to maintain their daily life; this includes support from their children, necessities, and subsidies from the government and other NGOs.

Health maintenance was the major reason given for undergoing regular physical exams and buying health supplement products (see Table 3). Although a higher percentage of the old-old group received regular checkups, fewer of them cited health maintenance and more of them cited others' request as their reasons. Older adults are in worse health condition (4), which may lead to a

Table 4 | Reasons for buying/not purchase health supplement products.

\begin{tabular}{|c|c|c|c|c|}
\hline & $\begin{array}{c}\text { Total }(N=982) \\
N(\%)\end{array}$ & $\begin{array}{c}50-69(N=493) \\
N(\%)\end{array}$ & $\begin{array}{c}70 \text { and over }(N=488) \\
N(\%)\end{array}$ & $p$-Value \\
\hline \multicolumn{5}{|l|}{ Why do you purchase health supplement products? ${ }^{a}$} \\
\hline Health & $247(66.4)$ & $149(68.3)$ & $98(63.6)$ & $0.037^{*}$ \\
\hline Recommended by family members or friends & $81(21.8)$ & $44(20.2)$ & $37(24.0)$ & \\
\hline Recommended by medical professionals & $76(20.4)$ & $36(16.5)$ & $40(26.0)$ & \\
\hline Family members or friends have bought & $39(10.5)$ & $23(10.6)$ & $16(10.4)$ & \\
\hline Advertisement & $38(10.2)$ & $28(12.8)$ & $10(6.5)$ & \\
\hline Low cost & $4(1.1)$ & $4(1.8)$ & 0 & \\
\hline Habit & $2(0.5)$ & $2(0.9)$ & 0 & \\
\hline \multicolumn{5}{|c|}{ Why do you not purchase health supplement products? ${ }^{a}$} \\
\hline Not effective & $279(46.3)$ & $140(51.7)$ & $139(41.9)$ & 0.107 \\
\hline Too costly & $143(23.7)$ & $58(21.4)$ & $85(25.6)$ & \\
\hline No faith in the products & $96(15.9)$ & $36(13.3)$ & $60(18.1)$ & \\
\hline Perceived good health already & $56(9.3)$ & $29(10.7)$ & $27(8.1)$ & \\
\hline No need & $55(8.8)$ & $26(9.6)$ & $27(8.1)$ & \\
\hline Do not want to rely on health food & $30(5.0)$ & $12(4.4)$ & $18(5.4)$ & \\
\hline Do not want to eat health food & $18(3.0)$ & $6(2.2)$ & $12(3.6)$ & \\
\hline Offered by hospital or clinic & $9(1.5)$ & $3(1.1)$ & $6(1.8)$ & \\
\hline Not recommended by medical professionals & $8(1.3)$ & $2(0.7)$ & $6(1.8)$ & \\
\hline
\end{tabular}

Chi-square was used.

${ }^{*} p<0.05$ was considered to be statistically significant.

${ }^{a}$ Multiple responses. 
higher chance of their seeking regular physical exams. This would suggest that health is not the main concern in the old-old group when compared with the young-old group. In addition, autonomy declines with increasing age (12), thus older adults have a greater chance of having their decisions made by others. The major reasons given by participants for not having regular physical checkups or buying health supplement products were lack of need and high cost (see Tables 3 and 4). Also, a higher percentage of the old-old group cited high cost as their reason for not having regular physical checks and not buying health supplement products. This would explain the phenomenon, whereby, although the oldold group has less spending money available, they still consider themselves to have enough for the necessities of daily life. Two of the expenses they tend to eliminate are regular health checks and health supplement products, suggesting that the old-old group does not perceive these to be necessities of daily life.

As shown in Table 3, there was a difference between the two groups in terms of introducing health supplement products to others. A higher percentage of the young-old group would do so compared to the old-old group. One reason is that the oldold group is more focused on purchasing medical equipment and drugs than the young-old group: because medical equipment and drugs are specific to different patients with different needs and concerns, they are more difficult to share with others than, for example, health food, which is not tailor-made and more likely to be of interest to others. Another reason is that older adults have poor health condition and mobility $(4,13)$, causing them to engage in fewer social activities $(14,15)$ and limiting their social activities to meeting a few people in the park, the older adult community center, and the immediate neighborhood. This may limit their ability to introduce health products and equipment to others. Because of this and the nature of the products they use, the old-old group is less likely to introduce health products to others.

Although fewer among the old-old group tended to introduce products to others, they were more likely than the young-old group to try products that others introduced to them. One possible explanation is that the old-old group has impaired decisionmaking ability (10), and information regarding health-related products is too complex, thus they tend to rely on the recommendations of others. This is in contrast to some research (16) suggesting that conformity decreases with increasing age. However, the present research focuses on a type of decision-making that requires high cognitive ability to analyze; if the process of analysis fails, they rely on other people's recommendations.

The major reasons for not undergoing regular physical exams and not buying health supplement products were the perceptions that they did not need them and that the products were not effective, or that the person had no faith in them. This suggests that information regarding a product is not always distributed to participants, and also that there was no heuristic to facilitate the decision-making process. Until people have enough information about a product to ensure that it is safe, useful, and effective, or until they have a self-perceived reliable heuristic, they prefer to do nothing (17).

The present research findings suggest that the stereotype of health supplement consumer behavior needs to be changed when marketing products and drugs to the old-old group. The concept of active aging, as introduced by the WHO, considers aging as an active process in spite of its inevitability (18). Under this framework, health is still a major concern to older adults, more so than to younger adults as older adults are in comparatively poorer health condition (4). To maintain health, regular physical checkups and health supplement products are necessities of daily life. However, because of the nature of aging, information needs to be framed for two separate groups. For the young-old, information can be presented in a more detailed way through appealing to reason, while for the old-old, information can be presented in more simple terms, emphasizing the need for the product; the old-old needs to be persuaded by appealing to their emotions (17). The costs of regular checkups and health supplement products need to be reduced for both groups according to the results of the present research in regard to available spending money.

\section{SUMMARY}

This study reveals the patterns of health supplement consumer behavior among the young-old and the old-old. The young-old and old-old have different patterns according to their different age-related health conditions and the amount of spending money available to them. Different educational programs concerning health consciousness and the promotion strategy of regular health checks and health-related products need to be tailored to young-old and old-old groups.

\section{ACKNOWLEDGMENTS}

The authors would like to thank all the study participants. Special thanks to the Senior Citizen Home Safety Association, Hong Kong, for providing financial support for this study.

\section{REFERENCES}

1. World Health Organization. Global Health and Ageing [Internet]. [cited 2013 Sep 13]. Available from: http://www.who.int/ageing/publications/global_health.pdf

2. United Nations. World Population Prospects, the 2012 Revision [Internet]. [cited 2013 Sep 13]. Available from: http://esa.un.org/unpd/wpp/

3. Census and Statistics Department (HKSAR). Hong Kong Population Projections 2012-2041 [Internet]. [cited 2013 Sep 25]. Available from: http://www.statistics. gov.hk/pub/B1120015052012XXXXB0100.pdf

4. Census and Statistics Department (HKSAR). Thematic Household Survey Report No. 50 [Internet]. [cited 2013 Sep 25]. Available from: http://www.statistics.gov. hk/pub/B11302502013XXXXB0100.pdf

5. World Health Organization. Milestones in Health Promotion: Statements from Global Conferences [Internet]. [cited 2013 Sep 13]. Available from: http://www. who.int/healthpromotion/en/index.html

6. Chen MF. Influences of health consciousness on consumers' modern health worries and willingness to use functional foods. J Appl Soc Psychol (2013) 43:E1-12. doi:10.1111/jasp.12033

7. Darian JC, Tucci L. Perceived health benefits and food purchasing decisions. J Consum Mark (2011) 28:421-8. doi:10.1108/07363761111165930

8. Chan K, Tsang L. Promote healthy eating among adolescents: a Hong Kong study. J Consum Mark (2011) 28:354-62. doi:10.1108/07363761111150008

9. Chan K, Tsang L, Leung V. Consumers' attitudes toward advertising by medical professionals. J Consum Mark (2013) 30:328-34. doi:10.1108/JCM-02-20130458

10. Drolet AL, Schwarz N, Yoon C. The Aging Consumer: Perspectives from Psychology and Economics. New York, NY: Routledge (2010).

11. Census and Statistics Department (HKSAR). 2011 Hong Kong Population Census [Internet]. [cited 2013 Sep 25]. Available from: http://www.census2011.gov.hk/ en/index.html 
12. Gaudencio J, Duarte Silva ME, Doria I. Psychological well-being and autonomy in very old age: Findings from a study in the South of Portugal. In: JelencKrasovec S, Radovan M, editors. Intergenerational Solidarity and Older Adults' Education in the Community. The Third Conference of the ESREA Network on Education and Learning of Older Adults; 2012 Sep 19-21. Ljubljana: Faculty of Arts at the University of Ljubljana (2012). p. 133-47. [Internet]. [cited 2013 Sep 25].

13. Schultz AB. Mobility impairment in the elderly: challenges for biomechanics research. J Biomech (1992) 25:519-28. doi:10.1016/0021-9290(92)90092-F

14. Buchman AS, Boyle PA, Wilson RS, Fleischman DA, Leurgans S, Bennett DA. Association between late-life social activity and motor decline in older adults. Arch Intern Med (2009) 169:1139-46. doi:10.1001/archinternmed. 2009.135

15. James BD, Boyle PA, Buchman AS, Bennett DA. Relation of late-life social activity with incident disability among community-dwelling older adults. J Gerontol A Biol Sci Med Sci (2011) 66:467-73. doi:10.1093/gerona/glq231

16. Pasupathi M. Age differences in response to conformity pressure for emotional and nonemotional material. Psychol Aging (1999) 14:170-4. doi:10.1037/08827974.14.1.170

17. Aronson E, Wilson TD, Akert RM. Social Psychology. Upper Saddle River, NJ: Prentice Hall (2010).
18. World Health Organization. Active Ageing: A Policy Framework [Internet]. [cited 2013 Sep 25]. Available from: http://whqlibdoc.who.int/hq/2002/WHO_NMH_ NPH_02.8.pdf

Conflict of Interest Statement: The authors declare that the research was conducted in the absence of any commercial or financial relationships that could be construed as a potential conflict of interest.

Received: 15 October 2013; paper pending published: 05 November 2013; accepted: 25 January 2014; published online: 10 February 2014.

Citation: Tse M, Chan KL, Wong A, Tam E, Fan E and Yip G (2014) Health supplement consumption behavior in the older adult population: an exploratory study. Front. Public Health 2:11. doi: 10.3389/fpubh.2014.00011

This article was submitted to Child Health and Human Development, a section of the journal Frontiers in Public Health.

Copyright (C) 2014 Tse, Chan, Wong, Tam, Fan and Yip. This is an open-access article distributed under the terms of the Creative Commons Attribution License (CC BY). The use, distribution or reproduction in other forums is permitted, provided the original author(s) or licensor are credited and that the original publication in this journal is cited, in accordance with accepted academic practice. No use, distribution or reproduction is permitted which does not comply with these terms. 